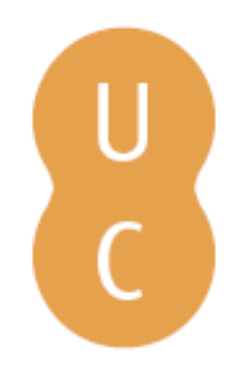

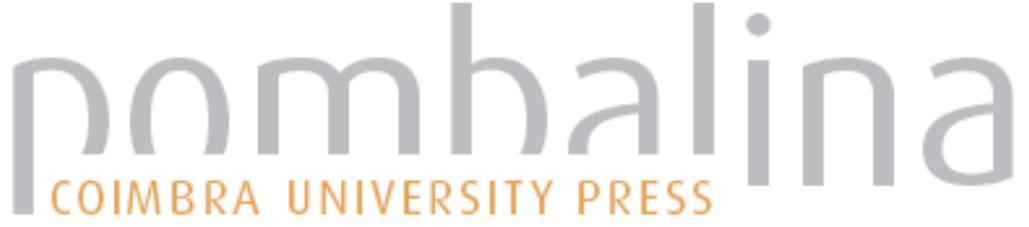

\section{Justiça e comunicação social: de costas voltadas}

Autor(es): Martins, António

Publicado por: Imprensa da Universidade de Coimbra

URL

persistente:

URI:http://hdl.handle.net/10316.2/38567

DOI:

DOI:http://dx.doi.org/10.14195/978-989-26-0770-2_6

Accessed : $\quad$ 26-Apr-2023 11:53:11

A navegação consulta e descarregamento dos títulos inseridos nas Bibliotecas Digitais UC Digitalis, UC Pombalina e UC Impactum, pressupõem a aceitação plena e sem reservas dos Termos e Condições de Uso destas Bibliotecas Digitais, disponíveis em https://digitalis.uc.pt/pt-pt/termos.

Conforme exposto nos referidos Termos e Condições de Uso, o descarregamento de títulos de acesso restrito requer uma licença válida de autorização devendo o utilizador aceder ao(s) documento(s) a partir de um endereço de IP da instituição detentora da supramencionada licença.

Ao utilizador é apenas permitido o descarregamento para uso pessoal, pelo que o emprego do(s) título(s) descarregado(s) para outro fim, designadamente comercial, carece de autorização do respetivo autor ou editor da obra.

Na medida em que todas as obras da UC Digitalis se encontram protegidas pelo Código do Direito de Autor e Direitos Conexos e demais legislação aplicável, toda a cópia, parcial ou total, deste documento, nos casos em que é legalmente admitida, deverá conter ou fazer-se acompanhar por este aviso.

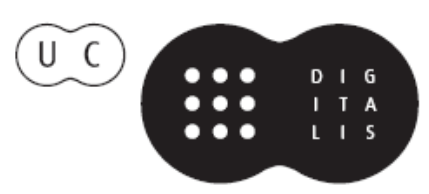



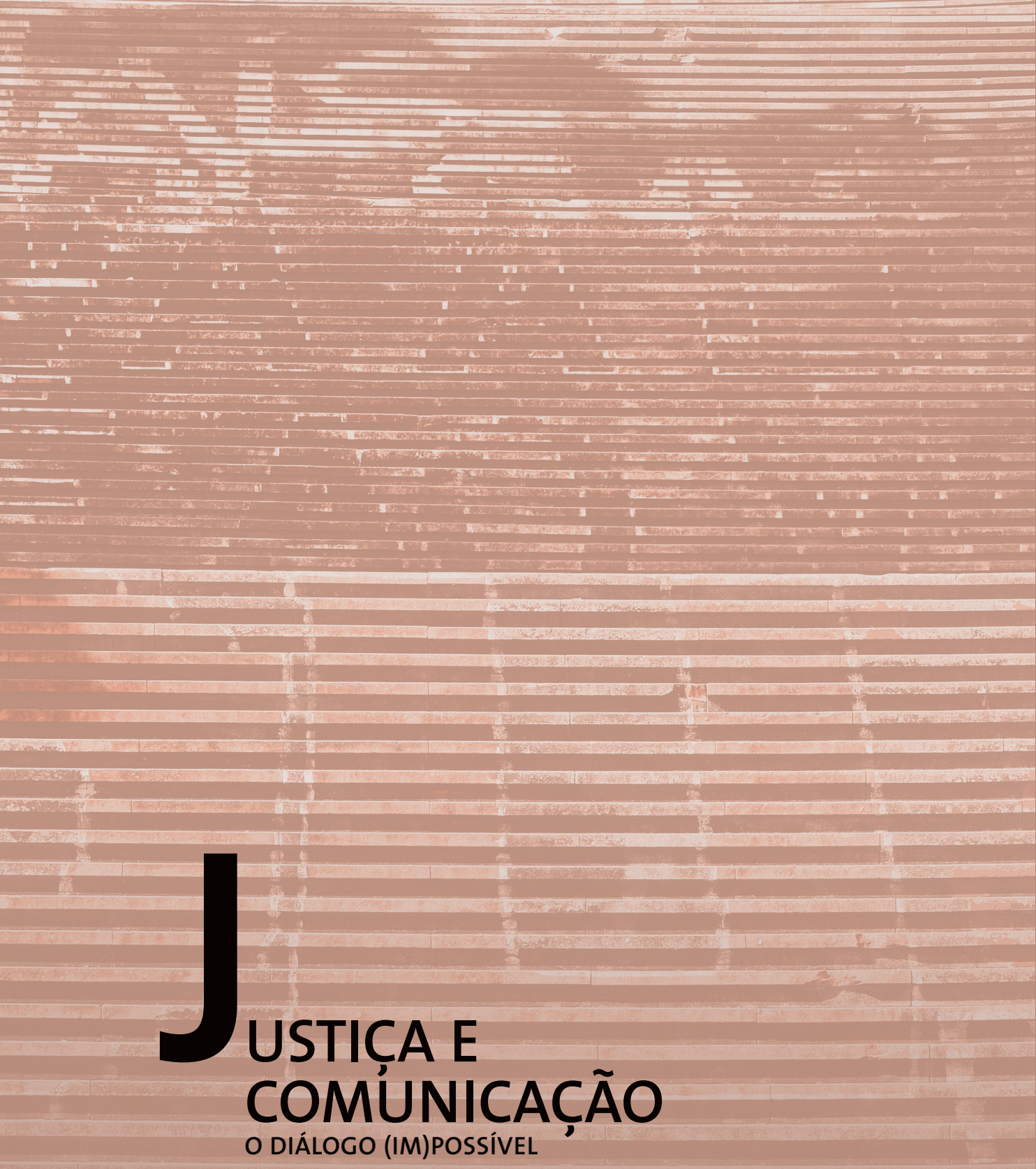

Rita Basilio Simões

Carlos Camponez

Ana Teresa Peixinho

ORGANIZAÇÃO 


\section{António Martins}

(Presidente da Associação Sindical dos Juízes Portugueses)

\section{JUST I ÇA E COMUNICAÇ ÃO SOCIAL: DE COSTAS VOLTADAS 154}

O espírito com que procurei enquadrar a minha intervenção, além do olhar socioprofissional de um juiz, dado que foi isso o que me foi solicitado, será também o de um cidadão preocupado com o débil e pouco saudável relacionamento entre Justiça e Comunicação Social, assumindo pois aqui uma responsabilidade cívica de contribuir, na medida do que possa valer a minha experiência profissional e o sentimento de cidadão comum, com um olhar crítico, mas com a esperança de que o futuro nos traga melhorias nesta relação.

Comecei a atividade de juiz numa época em que a comunicação social pouco tempo e espaço dedicavam à Justiça, quer aos temas da área em sentido político (a política da Justiça), quer aos casos que eram objeto de apreciação e decisão nos Tribunais (a realização da Justiça pelos Tribunais). O pouco espaço e tempo concedido iam para referências breves e bastante objetivas respeitantes à criminalidade comum (os crimes passionais e criminalidade violenta).

Gradualmente, a partir dos finais da década de 80/inicio da década de 90, com a investigação a incidir sobre criminalidade económico-financeira e tendo por suspeitos pessoas com elevado estatuto social, económico e/ou político, e também com o advento dos canais privados de televisão,

${ }^{154}$ Este texto respeita a comunicação apresentada ao colóquio Justiça e Comunicação que deu o mote a este livro, decorrido a 3 de Junho de 2011 na Universidade de Coimbra. Na qualidade de presidente da Associação Sindical dos Juízes Portugueses, António Martins integrou a mesa redonda Olhares Socioprofissionais integrada no encontro científico da iniciativa conjunta da Secção de Comunicação do Departamento de Filosofia, Comunicação e Informação da Faculdade de Letras da Universidade de Coimbra e o Conselho Superior da Magistratura. 
a comunicação social descobriu a Justiça e esta passou a ser um "filão" inesgotável de notícias, com uma competição desenfreada pela "manchete mais bombástica" ou pelo caso capaz de alcançar o maior "share" televisivo.

Esta paixão da comunicação social pela Justiça (para utilizar aqui uma imagem), ao contrário do que acontece com as paixões de verão, não esmoreceu. Mas também não deu lugar a um amor sólido e estável. O que temos hoje é uma relação em que a Comunicação Social e a Justiça estão de costas voltadas, relação semelhante à daqueles casais sempre zangados, embora com momentos breves de paixão violenta. Uso estas imagens porque são aquelas que a meu ver melhor retratam a realidade, que consiste numa fraca comunicação entre a Justiça e a Comunicação Social e um relacionamento pouco salutar entre ambas.

Diga-se, porém, e desde já que não considero que a culpa deste estado de coisas seja exclusiva da comunicação social.

Tal como em todas as coisas da vida que envolvem relacionamentos há, em regra, responsabilidade de ambos os lados.

$\mathrm{Na}$ verdade, a generalidade dos setores da Justiça não perceberam a mudança que se estava a operar com a apetência da comunicação social pelos casos e pelas matérias da Justiça.

Durante muitos anos, demasiados anos, a Justiça não se preparou para se relacionar com a comunicação social, mantendo-se numa atitude inerte e passiva.

Salvo alguns setores, como na área das polícias, o caso da Polícia Judiciária, e, no âmbito do Ministério Público, a Procuradoria Geral da República, que passaram a ter gabinetes de imprensa ou assessores de imprensa, o resto dos sectores da justiça, nomeadamente o Conselho Superior da Magistratura e os Tribunais, continuaram sem rosto nessa comunicação e, pior do que isso, sem regras para comunicar com a sociedade, especialmente através da comunicação social.

Não houve a capacidade para percecionar que a comunicação social tinha passado a ser o veículo essencial para transmitir o que se fazia nos tribunais: ministrar a Justiça em nome do Povo.

Não houve a perceção de que a clássica fórmula de comunicar através das audiências, do conhecimento direto para a comunidade e através da 
comunidade - as testemunhas e as partes dos casos e os seus advogados, na relação estrita destes com os clientes, assim como alguns cidadãos que assistiam às audiências - tinha sido substituída.

Igualmente não houve lucidez de análise para percecionar que esse novo veículo de comunicar a atividade desenvolvida pelos Tribunais, a comunicação social, passou também a ser uma forma de escrutínio social e público e, consequentemente, uma forma de legitimação do próprio sistema de Justiça. Ou deslegitimação da Justiça e dos seus atores, no caso de mau uso da comunicação por parte de quem faz comunicação social ou de quem instrumentalize a comunicação social para esse fim.

O resultado não podia ser senão aquilo que veio a ocorrer. Ou seja, como o sistema de Justiça não comunicava com a Comunicação Social foi substituído por outros interlocutores e a comunicação social passou a socorrer-se de outros atores do sistema, como polícias, advogados e as próprias partes, usando-as como fontes, bem como a usar "fontes não identificadas ligadas à investigação”.

Ora a generalidade destas fontes está interessada num resultado, seja o de mostrar e valorizar o seu trabalho, seja o de criar simpatia e compreensão, na opinião pública, pela sua causa ou caso ou pela sua posição. A consequência foi assistir-se, por vezes, demasiadas vezes, à instrumentalização da comunicação social.

Pouco a pouco começou a haver a perceção da necessidade de inverter esta atitude do sistema de Justiça e, ainda que de forma incipiente ou pouco adequada aos ritmos da informação dos tempos de hoje, começam já a surgir comunicados e esclarecimentos do CSM e mesmo declarações de responsáveis deste órgão, em que dão conta de informações sobre decisões dos Tribunais ou posições do CSM e transmitem esclarecimentos perante notícias publicadas com dados incorretos.

Aliás, embora não querendo colocar a questão em termos de reivindicar méritos ou algo semelhante, a verdade é que esta mudança de atitude começou com a própria ASJP que, no seu sítio da internet (www.asjp. pt), passou a disponibilizar na área, "Para a Comunicação Divulgação de decisões judiciais", informação relevante sobre a Justiça e os Tribunais, nomeadamente decisões destes com repercussão ou interesse públicos. 
Sentimos essa absoluta necessidade perante um caso de manifesta manipulação da comunicação social: o chamado caso Esmeralda (irei voltar a este caso, mais à frente, quando analisar, de seguida, alguns comportamentos de alguma Comunicação Social e de alguns profissionais da comunicação social).

A partir daí e considerando que cada um dos Tribunais não estava preparado (e ainda hoje não estão em regra), para a divulgação daquela atividade e decisões e como forma de os cidadãos terem acesso a uma informação objetiva, completa e rigorosa, assim como a própria comunicação social ter também acesso à mesma, assumimos que era responsabilidade do associativismo dos juízes colmatar tal lacuna e contribuir para que os cidadãos pudessem ter acesso a uma informação objetiva (nunca emitimos nesse espaço qualquer juízo de valor ou opinião), completa (não apenas parcial ou tendenciosa) e rigorosa (não especulativa) sobre a atividade e as decisões dos Tribunais.

Abriu-se entretanto uma porta de esperança num melhor desempenho dos Tribunais nessa comunicação.

Com efeito, o novo modelo de organização dos Tribunais, com comarcas de uma outra dimensão e escala e com um juiz presidente, que passou a ser o rosto visível do Tribunal para a comunidade e perante a qual tem responsabilidades, poderão permitir que o mesmo, ou alguém por si nomeado, desempenhe tais tarefas, mantendo o juiz ou juízes do caso resguardados. O exemplo do que ocorreu na Comarca do Baixo Vouga a propósito do chamado caso "Face Oculta" é um bom sinal de que melhores tempos virão no relacionamento entre a Justiça e a Comunicação Social.

Mas, como acima afirmei, creio que o atual estado de coisas que consiste num deficiente relacionamento entre Justiça e Comunicação Social é responsabilidade de ambos os sectores e dos respetivos profissionais.

Irei procurar analisar, de seguida, alguns comportamentos de alguma Comunicação Social e de alguns profissionais da comunicação social. Previamente cumpre deixar bem claro que tal análise não é uma crítica a todos os profissionais de comunicação social ou a esta, no seu conjunto.

Considero e tenho muito apreço por vários e excelentes jornalistas, profissionais sérios, isentos, objetivos e independentes. Também não tenho 
dúvidas que é fundamental, para termos uma sociedade democrática de qualidade, termos previamente uma comunicação social livre e capaz de assumir, em pleno, o seu papel de informar.

Mas não tenho dúvidas que nas relações entre a Justiça e a Comunicação Social também há muito a fazer, por parte do sector e dos profissionais da Comunicação Social.

Com efeito, o direito de informar não pode ser confundido com o mero sensacionalismo, o voyeurismo e outros fenómenos semelhantes, como o dos títulos de capa e das notícias que não têm qualquer suporte no conteúdo das mesmas e, às vezes, até são desmentidas por estas.

Também o direito de informar não pode deixar de tomar em consideração preocupações como o direito à honra, o direito à intimidade da vida privada, principalmente da vítima e da vítima-criança, assim como a presunção de inocência. Esta presunção de inocência não é e não pode ser vista apenas como um comando da lei processual para o juiz ou o Tribunal. É antes um direito constitucional, consagrado no $\operatorname{art}^{\circ} 32^{\circ} \mathrm{n}^{\circ} 2$ da Constituição, que a todos se impõe e, consequentemente, não pode o suspeito ou o arguido, enquanto não for condenado, ser tratado como culpado.

Confesso-vos que me preocupa muito a voracidade da comunicação social pelo início das investigações e dos inquéritos crime, máxime os primeiros interrogatórios judiciais e a menor atenção pelo julgamento e pelas decisões finais ou o quase nulo espaço e tempo para noticiar as absolvições (a não ser que estas possam dar mais uma manchete ou um share).

Permitam-me que vá buscar apoio nas palavras de outros para justificar e ilustrar o que quero dizer.

Num artigo recente, publicado na internet (em http://pt.scribd.com/ doc/48528222/Joao-Caupers), intitulado "Um caso sórdido ao gosto de uma informação reles", abordando a forma como a imprensa tinha tratado o caso da morte, em Nova York, do cronista social Carlos Castro, o Prof. João Caupers, da Faculdade de Direito da Universidade Nova, lastimava "a falta de vergonha da nossa comunicação social, com destaque para as televisões: há uma semana que os noticiários das 8 abrem com dez ou quinze minutos da "tragédia". Não as imagens horríveis das cheias no Brasil - que ficam sempre para depois -» ... e perguntava 
se é "para isto que serve a informação televisiva, incluindo a do canal público que nós pagamos” terminando, em jeito de desabafo, com duas perguntas: "a informação televisiva tem mesmo de ser esta espécie de teledifusor de lixo? Que raio se ensina nos cursos de comunicação e de jornalismo?"

Também o Prof. Universitário e Psiquiatra, Pio Abreu, em artigo publicado no Jornal Destak de 20.05.2011, questionava o mundo em que vivemos, isto a propósito da forma como o caso Dominique Strauss-Khan foi tratado pela imprensa, em que a "discrição e presunção de inocência, os alicerces do Direito, foram às urtigas" concluindo: "O circo romano, onde os estrangeiros incómodos eram lançados à arena para enfrentar as feras, antes de serem dizimados pelos gladiadores, voltou à aldeia global”.

Ou a forma como o Provedor do Leitor do Jornal Publico, José Queirós, na edição de 29.05.11 deste jornal, demonstrava "Quando a notícia desautoriza o título" e isto a propósito de uma notícia dessa semana em que manifestamente os factos, da própria notícia, não permitiam um título daqueles, ligando Eduardo Catroga a uma empresa denunciada por "suspeitas de subfacturação" e concluía: "Este é um caso em que títulos desajustados ... mancham uma notícia e poem em causa a reputação de independência e isenção de um jornal".

A comunicação social tem de assegurar um escrupuloso rigor e isenção, não só não permitindo ser usada e instrumentalizada, por alguém interessado em notícias reais ou em criar "notícias", como os profissionais de comunicação social não podem ser parte ou tomar partido por alguma das partes com interesses atendíveis, ou não, na notícia.

Volto aqui ao Caso Esmeralda, que acima referi, paradigmático do que não pode ocorrer, ou seja, a imprensa, nomeadamente a televisiva, a querer transformar o caso num paradigma dos "bons" e dos "maus", como se o mundo fosse "preto" ou "branco" e a vida não fosse feita de tons cinzentos. Claramente adotando partido por uma família em completo preconceito contra outra. Numa cruzada contra os Tribunais e as decisões judiciais, num arregimentar de "peritos", "especialistas" e importantes pessoas, em termos sociais, pretendendo criar, ao lado do tribunal, um outro espaço, o mediático, onde o caso haveria de ter 
outra solução. Em relação a algumas peças jornalísticas a propósito do caso, feitas por profissionais de comunicação de áreas que não tinham nada a ver com a Justiça e Tribunais, ficou até a sensação que houve o propósito, consciente, de manipular os factos.

Um outro exemplo, paradigmático, desta atitude de alguma comunicação social e de alguns profissionais de tomarem partido por uma das partes com interesse no caso objecto da notícia e até de assumirem a função de decisores, naturalmente melhores do que os juízes, ocorreu com uma reportagem inserida num espaço noticioso da RTP, intitulada "Filha Roubada", a propósito de uma decisão proferida pelo Tribunal de Fronteira em relação a uma criança, num processo de regulação do poder paternal (agora designado de responsabilidades parentais).

Mas mais do que as minhas considerações sobre tal exercício de "jornalismo" deixo apenas nota de que, na sequência de queixas apresentadas à Entidade Reguladora da Comunicação Social sobre aquela reportagem exibida na RTP, o Conselho Regulador desta entidade, por decisão de 16.12.2010 deliberou:

"1. Considerar as queixas procedentes, por incumprimento dos deveres ético-legais do jornalismo, designadamente o respeito pelos princípios do rigor informativo, de separação entre factos e opiniões e de auscultação de todas as partes com interesses atendiveis.

2. Instar a RTP a, doravante, em peças jornalísticas:

i) assegurar o direito à reserva da intimidade da vida privada, nomeadamente quando estiverem em causa crianças e jovens, e não divulgar elementos que permitam a sua identificação;

ii) não recolher imagens e sons com recurso a meios não autorizados, com a única exceção de situações em que se verifique um estado de necessidade para a segurança das pessoas envolvidas e quando o interesse público o justifique;

iii) garantir o dever de informar com rigor e isenção, não sufragando o ponto de vista de qualquer dos intervenientes, e procedendo a uma seleção de factos a noticiar que permita uma compreensão mais equilibrada e correta do conflito em causa”. 
Nada de confusões, porém. Para que não se criem dúvidas, faço notar que não sou adepto da posição de que quem considera que os Tribunais e as suas decisões não têm que ser objeto de controle social e, nomeadamente, da comunicação social, por existir o controle interno processual, das partes e dos recursos.

Muito pelo contrário. Não tenho dúvidas em subscrever a ideia de que os Tribunais estão, e devem estar, sujeitos ao escrutínio público e da comunidade, devem observar regras de transparência nos seus procedimentos, nos julgamentos e na publicitação das suas decisões - sem prejuízo dos casos em segredo de justiça - e que a comunicação social desempenha um papel fulcral e insubstituível nesse escrutínio social.

Mas o que a comunicação social não pode, e os jornalistas não devem, é querer substituir-se aos tribunais.

Creio, também, que é altura de haver uma comunicação social e, acima de tudo, profissionais da comunicação social que tenham formação específica na área da Justiça, que lhes permita apreender, compreender, descodificar e transmitir as questões, os casos, as especificidades, técnicas ou legais, numa linguagem acessível ao destinatário da comunicação.

É verdade que o sistema de Justiça e nomeadamente os Tribunais também devem encontrar forma de melhor comunicar e de as próprias decisões judiciais não serem tão herméticas. Mas nunca podemos esperar que a linguagem a usar nos atos judiciais - como nos atos médicos ou em qualquer ciência - seja a mesma do cidadão médio, sob pena de as questões jurídicas não poderem ser discutidas e tratadas adequadamente, em termos jurídicos.

Definitivamente, não é compatível com um mínimo de rigor e de profissionalismo continuarmos a ver/ouvir que foi realizado o "debate introdutório" e não o "debate instrutório" ou que "o arguido foi absolvido com uma pena suspensa”.

Eu sei que não ajuda nada a cada vez maior precariedade dos profissionais da comunicação social, que lhes retira possibilidade de formação contínua ou específica, mas creio que é altura de os proprietários dos meios de comunicação social perceberem que a qualidade pode fazer a diferença, até na sobrevivência. 
Cumpre-me terminar.

E não quero deixar de o fazer reafirmando o que disse no início desta comunicação: tenho esperança que o futuro nos traga melhorias nesta relação e interação entre a Justiça e a Comunicação Social, o que será sinónimo de uma sociedade democrática mais aprofundada e de melhor qualidade, em que a Justiça e a Comunicação Social não estejam mais de costas voltadas mas antes caminhem, não digo de braço dado, mas cada uma fazendo o seu caminho tendo ambas, no horizonte, valores que perseguem e dos quais vivem, como os do rigor, da isenção, da objetividade e do respeito pelos direitos dos outros.

E a realização deste Colóquio, colocando académicos e profissionais, da Comunicação Social e da Justiça, a refletir e a debater sobre o que todos podemos fazer para criar uma relação mais saudável e mais comunicativa entre a Justiça e a Comunicação Social, voltado para a comunidade, para os estudantes de Comunicação e Jornalismo e os profissionais da Justiça, creio que é um bom sinal no sentido dessa melhoria. 


\section{B I B L I O G R A F I A}

AFONSO, O. (2005). "Dever de reserva - O seu papel na jurisdição". In: AA VV, Balanço da reforma da acção executiva. Segredo de justiça e dever de reserva (Conselho Superior da Magistratura, II Encontro Anual - 2004). Coimbra: Coimbra Editora, pp. 147-154.

ALBINO, C. (2003). «Sim, a Ordem dos Jornalistas». In: Diário de Notícias, 2 de novembro.

AMSELEK, P. (1964). Méthode phénoménologique et théorie du droit. Paris: L.G.D. J.

ANTUNES, F. (1994). "Alta Autoridade está queimada». In: Jornal de Notícias, 14 de março.

AZNAR, H. (2005). Comunicação Responsável - A auto-regulação dos media. Porto: Porto Editora.

BARREIROS, J. A. (2005). "O dever de reserva nas profissões jurídicas». In: AA VV, Balanço da reforma da acção executiva. Segredo de justiça e dever de reserva (Conselho Superior da Magistratura, II Encontro Anual - 2004). Coimbra: Coimbra Editora, pp. 163-170.

BARTHES, R. (1984). O rumor da língua. Lisboa: Ed. 70, (trad. portuguesa).

BECKETT, K. e WESTERN, B. (2001). "Governing social marginality: welfare, incarceration and the transformation of state policy". In: Punishment and Society, 1, pp. 43-59.

BENHABIB, S. (2009). "Rumo a um modelo deliberativo de legitimidade democrática». In: MARQUeS, A. (ed.), A Deliberação Pública e suas Dimensões Sociais, Políticas e Comunicativas. Belo Horizonte: Autêntica Editora.

BERGEL, J-L. (1997). "Du concept de déontologie à sa consécration juridique». In: BERGEL, J-L, (org.), Droit et Déontologies Professionnelles. Aix-en-Provence: Librairie de l'Université.

BHATIA, V. K. (1993). Analysing Genre: Language Use in the Professional Setting. London: Longman.

BHATIA, V. K. (1994). Cognitive structuring in legislative provisions. In: GIBBONS, J. (ed.). Language and the Law. London: Longman.

BHATIA, V. K. (2010). Legal writing: specificity. Specification in legislative writing: accessibility, transparency, power and control. In: Coulthard, M. e Johnson, A. (eds.) 2010. The Routledge Handbook of Forensic Linguistics. London: Routledge.

BIRESSI, A. e NUNN, H. (2003). "Video justice: crimes of violence in social/media space». In: Space \& Culture, 6 (3): pp. 276-291.

BOBBIO, N. (1982). A teoria das formas de governo. Brasília: UnB.

BOBBIO, N. (2000). O futuro da democracia. São Paulo: Paz e Terra.

BOHMAN, J. (2000). "The division of Labor in Democratic Discourse: Media, Experts, and Deliberative democracy». In: Chambers, S. and Costain, A. N. (org). Deliberation, Democracy and the Media. Maryland: Rowman \& Littlefield Publishers. 
BOTTOMS, A. E. (1995). «The philosophy and politics of punishment and sentencing». In: Clakson, C. and Morgan, R. (eds.). The Politics of Sentencing Reform. Oxford: Clarendon Press.

BRES, J. (2005). "Savoir de quoi on parle: dialogue, dialogal, dialogique; dialogisme, polyphonie...» In: Bres, J.; Haillet, P.P.; Mellet, S.; Nølke, H. e Rosier, L. (dirs.). Dialogisme et polyphonie. Approches linguistiques. Bruxelles: De Boeck.

BRKIC, J. e ANDERSON, N. (1988). Drafting and Interpreting Legal Documents. In: Kevelson, R. (ed.). Law and Semiotics. Vol. 2. New York: Plenum Press.

CALHOUN, C. (1996). "Introduction: Habermas and the public sphere». In: Calhoun, C. (ed.) Habermas and the Public Sphere. 4. ${ }^{\mathrm{a}}$ ed., Cambridge: MIT Press, pp. 1- 48.

CAMPS, V. (2004). «Instituiciones, agencias y mecanismos de supervisión mediática». In: CONILL SANCHO, J.; GONZÁLEZ, V. (coords.). Ética de los Medios - Una apuesta por la ciudadanía audiovisual. Barcelona: Editorial Gedisa.

CANIVET, G. e JOLY-HURARD, J. (2004). La déontologie des magistrats. Paris: Dalloz.

CANotilho, G. e MOReira, V. (2007). Constituição da República Portuguesa Anotada, vol. I. Coimbra: Coimbra Editora.

CARAPINHA, M. C. (2006). Contributos para a análise da linguagem jurídica e da interacção verbal em sala de audiências. Dissertação de Doutoramento (não publ.). Coimbra: Faculdade de Letras.

CARMO, R. do (2005). "O dever de reserva - O dever de informar: algumas achas para o debate». In: AA VV, Balanço da reforma da acção executiva. Segredo de justiça e dever de reserva (Conselho Superior da Magistratura, II Encontro Anual -2004). Coimbra: Coimbra Editora, pp. 155-162.

CARPINI, M. D. e WILliAMS, B. A. (2001). «Let Us Infotain You: Politics in the New Media Environment». In: Bennet, W. L.; Entman, R. M. (eds). Mediated politics: communication in the future of democracy. Cambridge: Cambridge University Press, pp. 160-181.

CASTELLS, M. (1999). O poder da identidade (A era da informação: economia, sociedade e cultura; v.2). São Paulo: Paz e Terra.

CHERMAK, S. M. (1995). Victims in the News. Crime and the American News Media. Boulder, San Francisco, Oxford: Westview.

CHIBNALL, S. (1977). Law-and-Order News: An Analysis of Crime Reporting in the British Press. London: Tavistock Publications.

CHRISTIE, G. C. (1964). "Vagueness and Legal Language». In: Minnesota Law Review, 48.

COHEN, J. (1997). Deliberative Democracy. Cambridge: MIT Press.

COHEN, J. (2009). "Deliberação e legitimidade democrática». In: Marques, A. (ed.). A Deliberação Pública e suas Dimensões Sociais, Políticas e Comunicativas. Belo Horizonte: Autêntica Editora.

COHEN, S. (2002). Folk Devils and Moral Panics. The Creation of the Mods and Rockers, 3. ${ }^{\mathrm{a}}$ ed. London, New York: Routledge.

COHEN, S. e YOUNG, J. (1973). The Manufature of News: Deviance, Social Problems and the Mass Media. London: Constable.

CONSELHO REGULADOR (2006). Parecer Relativo ao Anteprojecto da Proposta de Lei que Altera o Estatuto dos Jornalista - Parecer 2/2006.

CORNU, G. (2000). Linguistique Juridique. $2^{\text {a }}$. Ed. Paris: Montchrestien.

CORNU, D. (1994). Journalisme et Vérité. Genebra: Labor et Fides.

CORREIA, J. C. (2005). Sociedade e Comunicação: Estudos sobre Jornalismo e Identidades. Covilhã: UBI. 
COULTHARD, M. e JOHNSON, A. (2007). An Introduction to Forensic Linguistics. Language in Evidence. London: Routledge.

COUlthARD, M. e JOHNSON, A. (eds.) (2010). The Routledge Handbook of Forensic Linguistics. London: Routledge.

CURTIS, P. (2001). Jack the Ripper and the London press. New Haven: Yale University Press.

DOUGLAS, M. (1986). How Institutions Think. New York: Syracuse University Press.

DRYZEK, J. (2004). "Legitimacy and economy in deliberative democracy» In: Farrely, C. Contemporary Political Theory: a Reader. London: Sage.

DRYZEK, J. (2000). Deliberative Democracy and Beyond: Liberals, Critics, Contestations. Oxford: Oxford University Press.

DUBOUCHET, P. (1990). Sémiotique Juridique. Paris: PUF.

DUCROT, O. (1982). La notion de sujet parlant. In: Cahier du Groupe de Recherches sur la Philosophie et le langage, 2. Grenoble: Université de Grenoble.

DUCROT, O. (1984). Le Dire et le dit. Paris: Minuit.

DURKHeIM, É. (1977). A Divisão do Trabalho Social, Vol. 1, trad. de M. I. Freitas. Lisboa: Editorial Presença.

EAGLETON, T. (2000). Ideology: an Introduction. 7. ${ }^{\mathrm{a}}$ ed. London: Verso.

ELSTER, J. (1986). "The Market and the Forum: Three Varieties of Political Theory". In: Elster, J.; Hylland, A. (eds). Foundations of Social Choice Theory, Cambridge: Cambridge University Press, pp. 104-132.

ELSTER, J. (1998). Deliberative Democracy. Cambridge: Cambridge University Press.

ERICSON, R., BARANEK, P. e CHAN, J. (1989). Negotiating Control: A Study of News Sources. Toronto: University of Toronto Press.

ESSER, F. (1999). "Tabloidization of news. A comparative analysis of Anglo-American and German Press Journalism». In: European Journal of Communication, pp. 291-324.

FARIA, J. E. (1986). "A Reforma do Ensino Jurídico». In: Revista Crítica de Ciências Sociais, 21.

FERNANDES, P. C. (2008). "Justiça e media: legitimação pela comunicação». In: Revista do CEJ $\left(n .^{\circ} 10\right)$, pp. 311-346.

FIGUEIREDO, C. e COSTA, R. (1990). "Alta Autoridade da discórdia». In: Expresso - Suplemento A4, 27 de janeiro.

FONSECA, J. (1994). "O lugar da Pragmática na Teoria e na Análise Linguísticas». In: Pragmática Linguística. Introdução, Teoria e Descrição do Português. Porto: Colecção Linguística/Porto Editora, n. ${ }^{\circ} 5$.

FOUCAUlT, M. (1991). Vigiar e Punir: Nascimento da Prisão. 9. ${ }^{a}$ ed., trad. de L. M. P. Vassallo. Petrópolis: Vozes.

FOX, R. L. e SICKEL, R. V. (2001). Tabloid Justice: Criminal Justice in an Age of Media Frenzy. London: Lynne Rienner Publishers Boulder.

FRANKLIN, B. (1997). Newszak \& News Media. London: Hodder Arnold.

FRASER, N. (1996). "Rethinking the public sphere: a contribution to the critique of actually existing democracy» In: Calhoun, C (ed.) Habermas and the Public Sphere. 4. ${ }^{a}$ ed., Cambridge: MIT Press, pp. 109-142.

FRIEDMAN, L. M. (1964-1965). Law and its Language. In: George Washington Law Review, p. 33.

FUENTES GONZÁLEZ, D. (1997). Algunas aportaciones de la sociolingüística al campo del derecho. In: Delgado León, F.; Calero Vaquera, M. L. e Osuna García, F. (eds.), (1998). 
Actas del II Simposio de Historiografía Lingüística. Córdoba: Servicio de Publicaciones de la Universidad de Córdoba.

GALVÃO TELLES, I. (2000). Introdução ao Estudo do Direito. Vol. II. 10 ${ }^{\mathrm{a}}$ ed. Coimbra: Coimbra Editora.

GARAPON, A. (1998). O guardador de promessas. Lisboa: Instituto Piaget.

GARLAND, D. (2001). The Culture of Control. Oxford: Oxford University Press.

GARMENT, S. (1991). Scandal: The Culture of Mistrust in American Politics. New York: Times Books.

GEYH, C. G. (2006). Preserving Public Confidence in the Courts in an Age of Individual Rights and Public Skepticism. http://ssrn.com/abstract=933699: Indiana University School of Law-Bloomington.

GIBBONS, J. (ed.) (1994). Language and the Law. London: Longman.

GIBBONS, J. (2003). Forensic Linguistics. An Introduction to Language in the Justice System. Oxford: Blackwell.

GIBBONS, J. e TURELL, M. T. (eds.) (2008). Dimensions of Forensic Linguistics. Amsterdam: John Benjamins Publishing Company.

GOLDMAN, L. (1994). Accident and absolute liability in anthropology. In: Gibbons (ed.). Language and the Law. London: Longman.

GOODRICH, P. (1987). Legal discourse. Studies in Linguistics, Rhetoric and Legal Analysis. London: Macmillan.

GRABER, D. A. (1980). Crime News and the Public. New York: Praeger.

GREER, C. e JEWKES, Y. (2005). "Extremes of Otherness: Media Images of Social Exclusion». In: Social Justice, 32 (1), pp. 20-31.

GREIMAS, A. J. (1976). Analyse sémiotique d'un discours juridique. In Greimas, A. J.. Sémiotique et sciences sociales. Paris: Seuil.

GRICE, P. (1975). Logic and Conversation. In: Cole, P.; Morgan, J. L. (eds.). Syntax and Semantics 3: Speech Acts. New York: Academic Press.

GUTMANN, A. e THOMPSON, D. (2007), "O que significa democracia deliberativa", In: Revista Brasileira de Estudos Constitucionais, Belo Horizonte, Ed. Fórum, 2007, pp. 17-78.

HABERMAS, J. (1996). Between Facts and Norms. Contributions to a Discourse Theory of Law and Democracy, Cambridge, MA: MIT Press.

HABERMAS, J. (1996), "Three Normative Models of Democracy» In: Benhabib, S. (ed.) Democracy and Difference. Princeton, NJ: Princeton University Press.

HABERMAS, J. (1997). Direito e Democracia - Entre facticidade e validade, vol. II. Rio de Janeiro.

HABERMAS, J. (1998). The Structural Transformation of the Public Sphere: An Inquiry into a Category of Bourgeois Society, 9. ${ }^{\mathrm{a}}$ reimp., trad. de T. Burger. Cambridge, MA: MIT Press.

HABERMAS, J. (2002). "Prefacio a la Nueva Edición Alemana de 1990". In: Historia y Crítica de la Opinión Pública: La Transformación Estructural de la Vida Pública, trad. de F. Gil Martín, $7^{\text {a }}$. reimp., Barcelona: Gustavo Gilli.

HALl, S., CRITCHER, C., JEFFERSON, T., CLARKE, J. e ROBERTS, B. (1978). Policing the Crisis: Mugging, the State, and Law and Order, London: The MacMillan Press.

HARRIS, S. (1994). Ideological exchanges in British magistrates courts. In: Gibbons, J. (ed.). Language and the Law. London: Longman.

HJARVARD, S. (2008). "The Mediatization of Society: a Theory of the Media as Agents of Social and Cultural Change». In: Nordicom Review 29, 2, pp. 105-134. 
HOEY, M (1985). "The Statute as Discourse and the Lawyer as Linguist». In: Hall, R. A. J. (ed.) The Eleventh LACUS Forum 1984. Columbia: Hornbeam Press.

HONNETH, A. (1995). The Fragmented World of the Social: Essays in Social and Political Philosophy. New York: SUNY Press.

HUTCHINGS, P. (1999). «Spectacularizing crime: ghostwriting the law». In: Law and Critique, 10: pp. 27-48.

JACKSON, B. S. (1995). Making Sense in Law. Linguistic, Psychological and Semiotic Perspectives. Liverpool: Deborah Charles Publications.

JALALI, C. (2005). "Nova governação nova cidadania? Os cidadãos e a política em Portugal». In: Revista de Estudos Politécnicos, vol. II, n. ${ }^{\circ} 4$.

JIMÉNEZ, F. J. (1994). «Posibilidades y limites del escandalo politico como una forma de control social». In: REIS Revista Española de Investigaciones Sociológicas, pp. 7-36.

KELSEN, H. (1934). "The pure theory of law, its methods and fundamental concepts". In: Law Quarterly Review, n. ${ }^{\circ} 50$.

KISSELER, L., e HEIDEMANN, F. (2006). «Governança pública: novo modelo regulatório para as relações entre Estado, mercado e sociedade?». In: Revista da Administração Pública, 40 (3), Rio de Janeiro, Maio/Junho.

LAMBERT, P. (2004). "Le devoir de réserve et les notions voisines». In: AA VV. Actes de la Table Ronde organisée par l' Institut d'Études sur la Justice, le 17 octobre 2003, Bruxelles: Bruylant, pp. 9-19.

LEVI, J. N. e WALKer, A. G. (eds.) (1990). Language in the Judicial Process. New York: Plenum Press.

MACHADO, H. e SANTOS, F. (2009). A moral da justiça e a moral dos media: Julgamentos mediáticos e dramas públicos (Oficina do CES $n .^{\circ} 333$ ). Coimbra: CES.

MACHADO, H. e SANTOS, F. (2008). Crime, drama e entretenimento. O caso Maddie e a meta-justiça popular na imprensa portuguesa (Oficina do CES n. ${ }^{\circ}$ 308). Coimbra: CES.

Machado, J. (2002). Liberdade de Expressão. Dimensões constitucionais da esfera pública no sistema social. Coimbra: Coimbra Editora.

MACHADO, J. B. (2002). Introdução ao Direito e ao Discurso Legitimador. (13 $3^{\mathrm{a}}$ reimp.) Coimbra: Almedina.

MALEY, Y. (1994). The Language of the Law. In: Gibbons, J. (ed.). Language and the Law. London: Longman.

MANIN, B. (1987). "On Legitimacy and Political Deliberation». In: Political Theory, 15, pp 338-368.

MANSBRIDGE, J. (1999). "Everyday talk in deliberative system» In: Macedo, S. (ed.). Deliberative Politics: Essays on Democracy and Disagreement. New York: Oxford University Press.

MARMOR, A. (2008). "What Does the Law Say?»In: Analisi e diritto 2007. Ricerche di giurisprudenza analitica. Torino: G. Giappichelli Editore.

MASCARENHAS, Ó. (1998) "Por uma carta 98 da auto-regulação». In: AAVV. $3 .^{\circ}$ Congresso dos Jornalistas Portugueses - Conclusões, teses, documentos, Lisboa, Comissão Executiva do III Congresso dos Jornalistas Portugueses.

MASON, P. (2006) «Lies, distortion and what doesn't work: monitoring prison stories in the British media». In: Crime Media Culture, 2 (3), pp. 251-267.

MATHIESEN, T. (1995). "The eagle and the sun: on panoptical systems and mass media in modern society». In: Ericson, R. (ed.) Crime and the Media. Aldershot, Brookfield USA, Singapore, Sydney: Dartmouth, pp. 333-350. 
MATHIESEN, T. (2004). Essays on the creation of Acquiescense in Modern Society, Winchester: Waterside Press.

MATHIESEN, T. (2006). Prison on Trial, $3^{\mathrm{a}}$. ed., Winchester: Waterside Press.

MATOS, F. A. (2011). Responsabilidade Civil por Ofensa ao Crédito ou ao Bom Nome. Coimbra: Almedina.

MESQUITA, J. (1998). "Aprofundar a autonomia", In: AAVV. 3. ${ }^{\circ}$ Congresso dos Jornalistas Portugueses - Conclusões, teses, documentos. Lisboa: Comissão do III Congresso dos Jornalistas Portugueses.

MOREIRA, V. (1997). Auto-Regulação Profissional e Administração Pública. Coimbra: Almedina, 1997.

NEWBURN, T. e JONES, T. (2007). "Symbolizing crime control». In: Theoretical Criminology, 11(2), pp. 21-243.

OLSSON, J.(2004). Forensic Linguistics. An Introduction to Language, Crime and the Law. London: Continuum.

PAIXÃO, B. (2010). O escândalo político em Portugal (1991-1993 e 2002-2004). Coimbra: Minerva.

PATON, W. R. (1922). Polybius: The Histories, Volume III, Books 5-8 (Loeb Classical Library). London: Heinemann.

PRATT, J. (2007). Penal Populism, London, New York: Routledge.

PUTMAN, E. (1997). "Éthique des affaires et déontologie des professions d'affaires: réflexions sur la morale des marchands». In: BERGEL, J-L. (org.). Droit et Déontologies Professionnelles. Aix-en-Provence: Librairie de l'Université.

RAWLS, J. (1971). A Theory of Justice. Harvard: Harvard University Press.

RAWLS, J. (2001). O Direito dos Povos. São Paulo: Martins Fontes.

RIVERA BEIRAS, I. (2003). "State form, labor market and penal system: the new punitive rationality in context». In: Punishment Society, 7(2), pp. 167-182.

SANDERS, L. (1997). "Against deliberation». In: Political Theory, 25, pp. 347-376.

SANTOS, B. S. et al. (2009). A Justiça Penal: Uma Reforma em Avaliação. Coimbra: Centro de Estudos Sociais da Faculdade de Economia da Universidade de Coimbra.

SCHLESINGER, P. e TUMBER, H. (1994). Reporting Crime: The Media Politics of Criminal Justice. Oxford: Clarendon Press.

SCHLESINGER, P., TUMBER, H. e Murdock, G. (1995). "The media politics of crime and criminal justice». In: ERICSON, R. (coord.) Crime and the Media. Aldershot, Brokfield USA, Singapore, Sydney: Dartmouth, pp 397-420.

SCHUDSON, M. (1978). Discovering the news: a social history of American newspapers. New York: Basic Books.

SCHULZ, W. (2004). "Reconstructing Mediatization as an Analytical Concept». In: European Jounal of Communication Vol 19 (1), pp. 87-101.

SCHUMPETER, J. A. (1994). Capitalism, Socialism, and Democracy. London: Routledge.

SERRANO, E. (2007). "Pensar a regulação dos media numa sociedade em mudança». In: Comunicação e Sociedade ("Regulação dos media em Portugal»), vol. 11, Braga.

SHAPIRO, I. (1999). "Enough of deliberation: politics is about interest and power". In: Macedo, S. (ed.), Deliberative Politics: Essays on Democracy and Disagreement. New York: Oxford University Press.

SHETREET, S. e DESCHÊNES, J. (eds) (1985). Judicial Independence; the contemporary debate. Amsterdam: Martinus Nijhoff. 
SILVA, A. S., (2007). "A hetero-regulação dos meios de comunicação social». In: Comunicação e Sociedade, vol. 11, Braga.

SILVA, V. J. (2006). "Ordem e desordem jornalística». In: Diário de Notícias, 29 de Março.

SILVEIRINHA, M. J. (2004). Identidades, Media e Política: O Espaço Comunicacional nas Democracias Liberais, Lisboa: Livros Horizonte.

SILVEIRINHA, M. J. (2005). "Democracia deliberativa e reconhecimento: repensar o espaço político». In: Correia, J. C. Comunicação e Política. Covilhã: UBI.

SOURIOUX, J-L e LERAT, P. (1975). Le langage du droit. Paris: PUF.

STOFFEL-MUNCK, P., (1997). "Déontologie et moral». In: Bergel, J-L. (org.), Droit et Déontologies Professionnelles. Aix-en-Provence: Librairie de l'Université.

STYGALL, G. (2010). "Legal writing: complexity. Complex documents/average and not-so-average readers". In: Coulthard, M.; Johnson, A. (eds.) (2010). The Routledge Handbook of Forensic Linguistics. London: Routledge.

SURETTE, R. (2010). Media, crime, and criminal justice: images, realities and policies. $4 .{ }^{a}$ ed. Belmont: Wadsworth.

THOMAS, J. (1997). Judicial Ethics in Australia. Sydney: Law Book Co.

THOMPSON, J. (2005). "The new visibility". In: Theory, Culture E Society, 22(6),pp. 31-51.

THOMPSON, J. B. (2002). O escândalo político: poder e visibilidade na era da mídia. Petrópolis: Editora Vozes.

THORNTON, G. C. (1996). Legislative Drafting. London: Butterworth.

THUSSU, D. K. (2007). News as entertainment: the rise of global infotainment. London: Sage.

TIERSMA, P. M. (1993). «Linguistic Issues in the law». In: Language, 69, pp. 113-137.

TIERSMA, P. M. (2000). Legal Language. Chicago: The University of Chicago Press.

VALIER, C. (2002). Theories of Crime and Punishment. Harlow, New York: Longman.

VAN DIJK, T. A. (1990). La Noticia como Discurso: Comprensión, Estructura y Producción de la Información, Paidós: Barcelona.

VAN DIJK, T. A. (2005). Discurso, Notícia e Ideologia: Estudos na Análise Crítica do Discurso, trad. de Z. P. Coelho, Porto: Campo das Letras.

VAN OMMESLACHE, P. (1995) “L'autorégulation». In: AAVV, L'Autorégulation. Bruxelas: Bruylant.

VERDUSSEN, M. (2004). "Le devoir de réserve au regard de la jurisprudence de la Cour Européenne des Droits de l'Homme». In: AA VV, Actes de la Table Ronde organisée par l' Institut d' Études sur la Justice, le 17 Octobre 2003. Bruxelles: Bruylant, pp. 21-31.

VILlEY, M. (1974). "Préface». In: Archives de Philosophie du Droit, Tome XIX.

VILLEY, M., KALINOWSKI, G. e GARDIES, J-L. (1974). "Indicatif et impératif juridiques. Dialogue à trois voix". In: Archives de Philosophie du Droit, Tome XIX.

VIRALlY, M. (1966). "Le phénomène juridique». In: Revue de Droit Public.

WACQUANT L. (2001). "How penal common sense comes to Europeans: notes on the transatlantic diffusion of neoliberal doxa». In: European Societies, 1 (3), pp. 319-352.

WEICHER, M. E. e GOLDSCHMIDT, J. (2007). "The Expansion of the First Amendment in Judicial Elections: Another Cause for Reform». In: Loyola University Chicago Law Journal, pp. 833-894.

WEICK, K. E. (1995). Sensemaking in Organizations. London: Sage. 
WIENER, J. (1988). Papers for the millions; the new journalism in Britain, 1850-1914. New York: Greenwood.

WIIO, O. A. (1995). "Organizational communication. Contingent views». In: Goldhaber G.M.; Barnett G. A. (eds.). Handbook of Organizational Communication. Norwood: Ablex.

WILliAMS, G. (1945). Language and the Law (artigo em 5 partes). In: The Law Quarterly Review 61 (4 partes) e 62 (5. ${ }^{\mathrm{a}}$ parte).

WOLTON, D. (1995). "As contradições do espaço público mediatizado". In: Revista de Comunicação e Linguagens, 21-22, pp. 167-188.

YOUNG, I. M. (2000). Inclusion and Democracy. Oxford: Oxford University Press. 